\title{
¿REGALOS VIRREINALES? A PROPÓSITO DE UN MUEBLE NAPOLITANO DE 1609
}

Se presenta aquí un nuevo mueble perteneciente a un grupo, en estrecha relación con la monarquía hispana durante el siglo XVII, en el intento de buscar algún indicio para poder confirmar la hipótesis de que este tipo de muebles constituyó realmente un regalo de la ciudad de Nápoles a cada virrey saliente, al menos durante los primeros veinte años del siglo XVII.

Desde 1975 Gonzalez Palacios, Renato Ruotolo y Dieter Alfter, figuran como los más destacados investigadores que dedicaron su atención a unos lujosos escritorios napolitanos realizados en ébano y palosanto con placas de marfil grabado con representaciones historiadas, series de emperadores y mapas, muebles manieristas firmados y fechados, atentos a una simbología precisa que, como demostraron estaba en estrecha relación con la casa de Austria. Los nombres de Giovanni Batistta da Curtis grabador en marfil "intagliatore d'avoglio", de Giovanni Fiammingo "scrittorista d'avolio"1 junto con otros maestros ebanistas flamencos o el de Gennaro Picicato, quizás cosmógrafo, los documentos publicados por el primero de estos estudiosos sobre los conciertos entre estos artistas, el conocimiento de otros entalladores en marfil Jacobo Manganiello y Petrus Pax, los manieristas encuadres arquitectónicos tan cercanos a las estampas que circulaban por toda Europa desde la escuela de Fontainebleu, y el seguimiento preciso de las series de estampas de Fontana y Tempesta, permitieron fechar los muebles de los museos de Hamburgo, Londres,

\footnotetext{
1 Jan van Santen, Giovanni De Santis, Giovanni Fiammingo o Vansanzio (Utrecht 1550-Roma 1621), activo en Roma quizás desde 1583 como maestro de hacer escritorios y maestro de obras, a quien se atribuye las fachadas del casino Borghese o de la villa Falconieri en Frascati, resueltos ambos como los frentes de los escritorios, cfr. Baglione Le Vite de' pittori, scultori et architeti dal Pontificato di Gregorio XIII del 1572 fino a tempi di papa Urbano Otavo nel 1642. Roma 1642. Thieme-Becker, ent. Vasanzio, a quien erróneamente S. Colombo le atribuye un mueble similar al que aquí se presenta en L'arte del legno e del mobile in Italia. 1981, $\mathrm{n}^{\circ} 303$.
} 
Filadelfia entre los años 1595-972. En la década de los noventa pudimos ampliar las obras de Giovanni Battista de Curtis, con una arqueta firmada y fechada en $1587^{3}$, y asimismo, ampliar el elenco de grabadores italianos en marfil como fue Antonio Spano, quien firmó un escritorio con escenas de la historia de Nápoles y quien se declaraba "cosmógrafo y criado de su majestad"4.

Como pertenecientes a un grupo en estrecha relación con estos, González Palacios incluyó otros dos escritorios un poco más pequeños, en el Museo de San Martino, que por tradición se venían considerando como regalos de la ciudad de Nápoles al duque de Alba, uno fechado en 1619 con la efigie de Felipe III y el otro con la de Felipe IV en 1623, junto con otro de 1621 depositado en el museo Poldi Pezzoli de Milán. En 1990 publicamos otro idéntico en una colección particular española, fechado en 1611 y reproduciendo en su frente a Don Juan de Austria y la batalla de Lepanto, casi idéntico a los citados en los museos italianos ${ }^{5}$. Los tres se cerraban con tapa abatible, ornada al exterior con un planisferio, mientras en su interior aparecian las efigies de todos sus reyes hasta esa fecha y el mapa del reino de Nápoles flanqueado por dos listas con los personajes más relevantes del reino. El frente de gavetas en los tres estaba formado por pequeños planos de ciudades famosas, incluyendo siempre el de Nápoles en lugar preeminente bajo la escena central. En algunas publicaciones posteriores, insistimos en la evidencia de la relación entre todos ellos, apuntando la posibilidad de que constituyeran regalos puntuales a los diferentes virreyes estantes en Nápoles durante el primer tercio del siglo XVII, de ahí las listas de los diferentes notables napolitanos en torno al mapa del Reino a partir del ejemplar de $1611^{6}$.

Estudiado más en profundidad el aspecto del regalo diplomático a lo largo de los siglos XVI y XVII ${ }^{7}$ la hipótesis del regalo virreinal se nos antoja perfectamente factible con la aparición de otro ejemplar prácticamente idéntico a los anteriores en colección particular española. En excelente estado de conservación, presenta tapa frontal abatible, decorada completamente un su exterior por un gran planisferio, soportado por Hércules con la piel del león sobre sus hombros, entre las cuatro partes del mundo, con la fecha de 1609 en el ángulo inferior derecho. El reverso de la misma ostenta un mapa del reino de Nápoles orlado por medallones de los reyes de Nápoles desde Ruggero II, centrado por la efigie de Felipe III, con la fecha de 1598. El interior distribuye cuatro

\footnotetext{
2 D.Alfter "Ein neapolitanischer Kabinettschrank des Giacomo Fiammingo (?) und Giovanni Battista De Curtis" Pantheon XXXVII, 1979, pp.135-141; A. González Palacios en Bolaffi-Arte (1975 y 1978) recogidos en Il tempio del gusto. Le arti decorativi in Italia fra classicismi e barocco. Roma e il regno delle Due Sicilie.Milano 1984, tomo I pp.239-247 y tomo II pp.182-185; R.Ruotolo "Mobili” en La Civiltá del Seicento a Napoli 363-372.

3 Posible regalo al que fue virrey de Nápoles entre 1587-95, don Juan de Zúñiga Avellaneda, conde de Miranda, sobrino del elogiado don Juan de Zúñiga y Requesens, principe de Petrapersia, a su vez virrey entre 1579-82 y que narra en escenas la actuación de ambos con motivo de las bodas de la infanta Catalina Micaela con el duque de Saboya, en Aguiló, M M $^{\mathrm{a}}$. "Una nueva obra de Giovanni Battista da Curtis:La arqueta de don Juan de Zúñiga Comendador Mayor de Castilla" Archivo Español de Arte, no 272, 1995, pp. 353-364.

4 Estante en la corte en Madrid, en la que su hijo Francisco continuó con el cargo de "entallador en marfil y reparador de escritorios" en Aguiló. "El esplendor de un reino: Nápoles y el mobiliario de lujo a la vuelta del siglo XVI" Archivo Español de Arte, no 258, 1992, pp. 179-199.

5 Aguiló "Mobiliario en el siglo XVII" en Mueble Español. Estrado y Dormitorio Comunidad de Madrid 1990 , pp.115-132 y Catálogo nº 47.

6 Aguiló “ Relaciones e influencias Nápoles-España en las Artes Decorativas entre el Manierismo y el Barroco. Künstlerischer Austausch zwischen Spanien und Neapel in der Zeit der Vizekönige, Mitteilungen der Carl Justi Vereinigung 1997 pp. 86-92 y “Conclusiones" en Arte e identidades culturales. Valencia: 1997. pp. 345-360.

7 Colantuono, A. "The Mute Diplomat” The Diplomacy of Art. Villa Spelmann Colloquia 7, Milano 2000. pp.51-76; Arte y Diplomacia de la Monarquía hispana en el siglo XVII. Coord. Jose Luis Colomer. Casa de Velázquez 2003 y Aguiló, "Relaciones entre España e Italia en el siglo XVII: la importación de objetos de lujo" Barcelona, Associació per a l'estudi del Moble (en prensa).
} 
gavetas a cada lado de un cuerpo central, con una portada entre dos columnas, cuyo zócalo es otro cajón y uno superior tras una balaustrada de marfil con remates de bolas (fig. 1). Todas las gavetas llevan sus frentes decorados con placas de marfil con planos grabados de ciudades, mientras que la portada recoge de nuevo la imagen de Felipe III en un carro tirado por cuatro caballos blancos en una vista frontal. Tras la balaustrada superior se situán dos medallones de perfil recortado con las efigies de Carlos V e Isabel de Portugal. Flanqueando el cajón inferior central, en los pedestales de las columnas aparecen representadas dos empresas: IAM ILLVSTRABIT OMNIA, y PROBANTUR FORTES IMPETV. Tras la portada central el espacio, ligeramente retranqueado está formado por cuatro gavetillas a cada lado y ocho al fondo que a su vez asemejan una portada en la que la figura central de un cazador va rodeada de escenas de caza de diversas especies, siempre con las figuras de cazadores, perros y cercas, todos con tiradores de metal. Las caras externas del mueble, chapeadas en palosanto se decoran con plaquillas alternando formas cuadradas, ovaladas y redondas, unidas entre sí por filetes y círculos de hueso, que recogen escenas del Antiguo Testamento tomadas literalmente de la serie correspondiente de AntonioTempesta, siendo este el único ejemplar que ostenta un interesante herraje en bronce dorado de excelente calidad, que podemos poner en relación con los dibujos napolitanos del mismo siglo.

El planisferio bajo el título de NOVA TOTIVS TERRARV ORBIS se corresponde con el del Theatrum de Abraham Ortelius, con la representación de las cuatro partes del mundo y los lunetos con placas en las que se describen geográficamente las mismas. Si bien aparecen colocadas de izquierda a derecha Asia, equivocadamente en primer lugar, Europa, América y África, las dos superiores están parcialmente tapadas por los pestillos, mientras que las inferiores llevan representaciones ptolemaicas, una el zodiacus con sus signos en el Ecuador y el otro América vista desde la Antártida, ombra della terra, y la cartela Neapoli Anno1609 bajo el dedicado a Africa ${ }^{8}$.

\footnotetext{
8 Asia secunda orbis pars, ad novo orbe oriente versus dividitur ac per tretum/ anianû ponigitur lapan insole ibidem posita at 13 gradû sub Aequino...fines cû / Africa Continens Vtantê Geograsphine Ordine Sequamur, Asia ab Ptolomeo in......Neo fe/rieis in quindicim partes dividitur Prima Continet Natoliam, quae et Asia minor dicitur sec/unda Masc...aimi... et Circassiam tertia Bagadath Quarta Siciam, Palaestinam et Arabiam de..... dam Quinta, Persiam Sexta, Arabia fel... Septima Tartaros Nigros et Re/gionem Caronza a Octava, Scytiam vel Tangut aut Cataium. Nona/ ......Regnum Anagosia e Decima, Idostan vel Indiam intra Gangem......Undecima Cardadam vel Macie Regnum cû Begala,/...... China Duodecimi Magi Decimoterzo / .... La pan aliasque insolas Decimocuarto / .......pobana Decimoquito Mon/....lucas

Orbis terrarum un quatuor dividitur partes Europam, Asia, Africam, et Americam minima / harem postium Europa. Cuius logitudinem ab Lustitaniae Promotorio, ad Tanaim Triamille / et Ottigenta Miliaria continet. Latittudinem vero ab Aegeo Mari, ad Oceanum Hibernicu / miliaria mille et ducentur. Eius Regiones tabulas decem constituit Ptolomaeus Neotorici duot / decim côstituere. Prima centinet Angliam Scotiâ, et Islandiam Secunda Hispaniam Tertia / Galiam Quarta, Germania Quinta, Helvetiam, Bavariam, Pannoniâ. Austriam / Hungariâ, Illyrin. Croatiam, Bosinâ Dalmatiam Sexta, Italiam Septima, Siciliam / atque Sardiniam Insulas. Octava Prusiiam, Lituania, Poloniam Nona / Noruegiâ et Suetiam Decima. Findemarchiam, Scrifi:/niam. Coreliam, et Russiâ albam Vndecima Azigorû / regiones quâ Septê Castra appellant Valachiam, Bu..../ garia et Transilvana: XII. Macedoniar... / Qua et Gretias cû multis / insulas.

America Quarta Orbis pars in duas partes divitur Peru et Novâ Hispana / Peru Septem continet Provincias Castiliam auri Pariam Quiliam Brasil Chile Plata / et Chimos, usque ad Tretum Magaglianes, quo ab terra incognita dividitur Nona Hispania, continet Nicoraguâ, Insulam Hispanam Cubam aliasque Insulas Guatamito / Mexicum vel Tesmistitan Floridam Xaliscum, Nova Galiciam Nova Franciam Bacalaos / Canada Cibolam, quitum ad Asiam partet occidentê versus Atque universus / Orbis Climata. Regnu Cuitates Montes Coles, Flumina Mares Partus Promoto /ria Insula intros Globo in planitie delineato exactissime proponuto.

Africa Tertiam Orbiam pars Asiae Orientem VeRsus contemina D. Mares Prom/notorio ad Mare pubrú et Trebam Bebelusque ad Meridianú cum Insulla Zocotura/ Et Madagascar, desceditq ad 44 gradus Antarticum nesu. Ab Ioanne Leone, in quatuor partes/ dividetu. Alej un Septem Tabulas devisore Prima habet, Barbariam et Aegyptum Secunda/ Numidiam Tertia Libiam Quarta Nigritarum Regionent, Quinta Guineam, Sextal Aethiopiam, Septima, Manicongum, finesq habet ad Bone Sepe Caput aliasq Insula. / NEAPOLI ANNO 1609.
} 


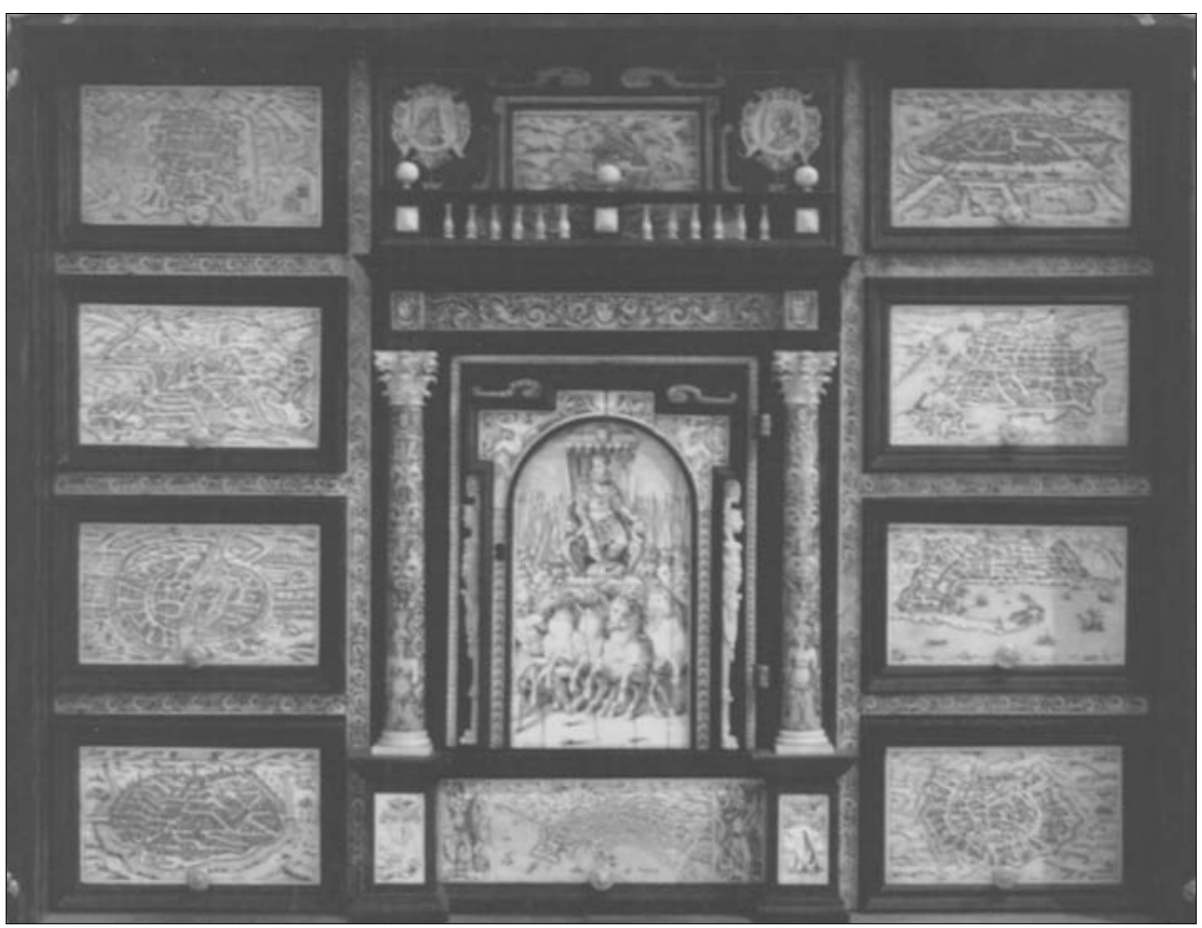

Figura 1. Escritorio. Frente de gavetas. Nápoles 1609. Colección particular.

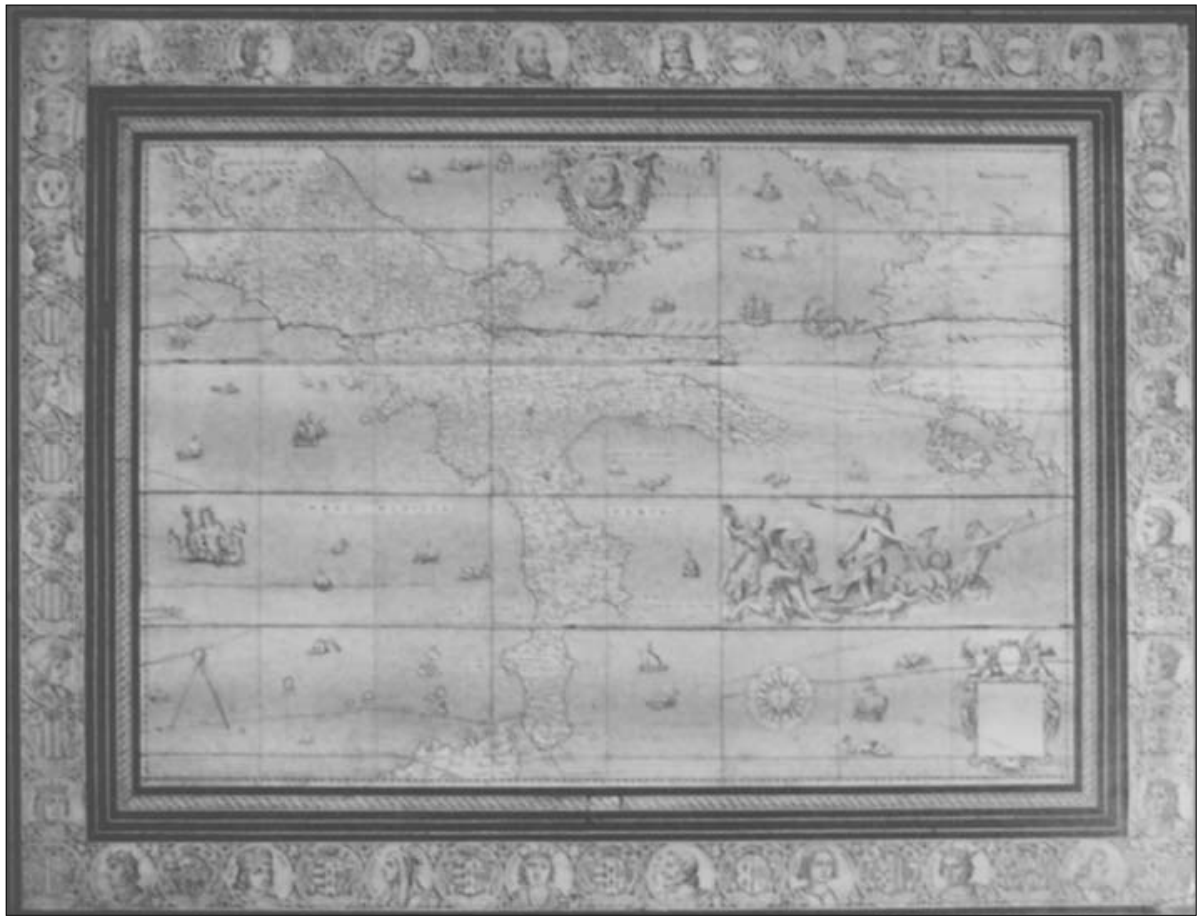

Figura 2. Mapa del Reino de Nápoles. Interior de la tapa.

AEA, LXXIX, 316, OCTUBRE-DICIEMBRE, 403-425, 2006, ISSN: 0004-0428 
El mapa del reino de Nápoles (fig. 2) que ocupa el interior de la tapa, rodeado por las medallas de los reyes de Nápoles y de sus correspondientes armas responde a la representación geográfica del reino, según la proyección de Mercator, indicándose los nombres de las principales ciudades, villas, pueblos, mares y accidentes geográficos. En la parte superior, centrando la composición, una guirnalda de laurel subraya la efigie de Felipe III, bajo una filacteria que reza REGNO DI NAPOLI. Bajo la medalla, en una cartela FILIPPO III D.G.CO / MINTIO A REGNARE LE ANNO 1598 ETALPTEREA y debajo MONTE ·S·ANGELO (fig. 2). En el mar Adriático se distribuyen barcos grandes de dos palos y otros pequeños de vela latina, sin aparejar, entre los que emergen delfines y cetáceos. En el tercio superior derecho continúa la proyección de la península macedónica incluyendo la isla de Creta, mientras en el golfo de Tarento se representa un grupo con Anfitrite en una nave arrastrada por dos delfines, un putto hace sonar una trompeta y un tritón rapta a otra nereida, Debajo la rosa de los vientos y unas cartela vacía enmarcada por dos amorcillos y espejo. En el mar Tirreno en cambio una sirena coronada (Colonna?), barcos navegando con las velas desplegadas y debajo un compás con la escala. La representación es la misma utilizada para otros escritorios similares: el de la colección Montortal de 1611, el conservado solo como placa en el Museo Civico Gaetano Filangieri ${ }^{9}$ y los dos del museo de San Martino de Nápoles solo que en todos ellos se reduce exclusivamente al reino de Nápoles ya que a ambos lados se distribuye la nómina de gobernadores, virreyes y nobleza del Reino en el momento de su realización, 1611, 1616, 1619 y 1621 respectivamente. Se pueden observar ligeras variantes entre todas ellas, más amplia y mejor distribuida la que presentamos hoy, en la que resaltamos también el que todas las efigies de los reyes de la orla miran hacia el centro de la composición, mientras en las demás lo hacen alternativamente a izquierda y derecha. La bella composición de Anfitrite, mas extendida que en las otras está muy cercana a las que Antonio Tempesta utiliza para rellenar los espacios vacíos de sus estampas ${ }^{10}$, la pequeña cartela, vacía en los de 1609, 1612 y 1616, aparece ampliada, con un largo texto en los de 1619 y 1621 situada en el único espacio disponible en ellas sobre el mar Tirreno, mostrando en su intención documental la pérdida de proporciones y distribución de espacios conseguida en esta de 1609.

Las ciudades representadas sobre las gavetas ${ }^{11}$, reproducen las incluidas en el Civitates orbis terrarum de Braun y Hogenberg (1572-1617), correspondiendo en general al primer volumen. Alguna como la de Sevilla (fig. 4), está tomada del grabado de Joris Hoefnagel para la edición de 1588, la de Nápoles del grabado de A. Lefreri y la de Mesina en cambio la encontramos igual en uno de los últimos volúmenes, en la vista grabada por Henry de Beauvan en 1615. El interés por las vistas de ciudades, aparte de por su interés por la cartografía, ya demostrado por Carlos V e Isabel de Portugal, fue asumido por Felipe II tras su segundo viaje a Flandes en 1556, cuando comienzan los envíos de instrumentos científicos por Arias Montano junto con "todas las descripciones y mapas estampados y puertos de lienzo que a V.M. parecieron y contentaron" en 1564, que se tradujeron al comienzo de las "Relaciones para la descripción general de España en 1574. Pero además esos panoramas "a vista de pájaro" alla manera dei Fia-

\footnotetext{
${ }^{9}$ Mateu Ibars, J. "Nómina de virreyes y nobleza del reino de Nápoles en una placa ebúrnea del siglo XVII" Boletín de la Real Academia de la Historia, 1956, pp. 61-78.

10 Bartsch vol 37 (17) I 465.

11 Nápoles, Sevilla, París, Palermo, Mesina, Toledo, Milán, Roma Amberes y Méjico.

12 Desde la Camara delle Citta del II marqués de Mantua en 1490 a las sala del mapamundi del palacio Farnesio en 1570 o las vistas de Italia del Belvedere vaticano de Gregorio VIII de 1578 , las que decoran los corredores del palacio del Viso del Marqués o si seguimos la descripción de L’Heremite los mas de setenta mapas de la edición de 1578 de Theatrum Orbis Terrarum de Ortelius que en 1592 ornaban el Salon del Trono del Alcazar cfr. en R.Kagan "Felipe II y los geógrafos" cap. II de "Las ciudades del siglo de Oro" en Las Vistas Españolas de Antón van der Wyngaerde ed. El Viso, Madrid 1986 pp.41-53.
} 


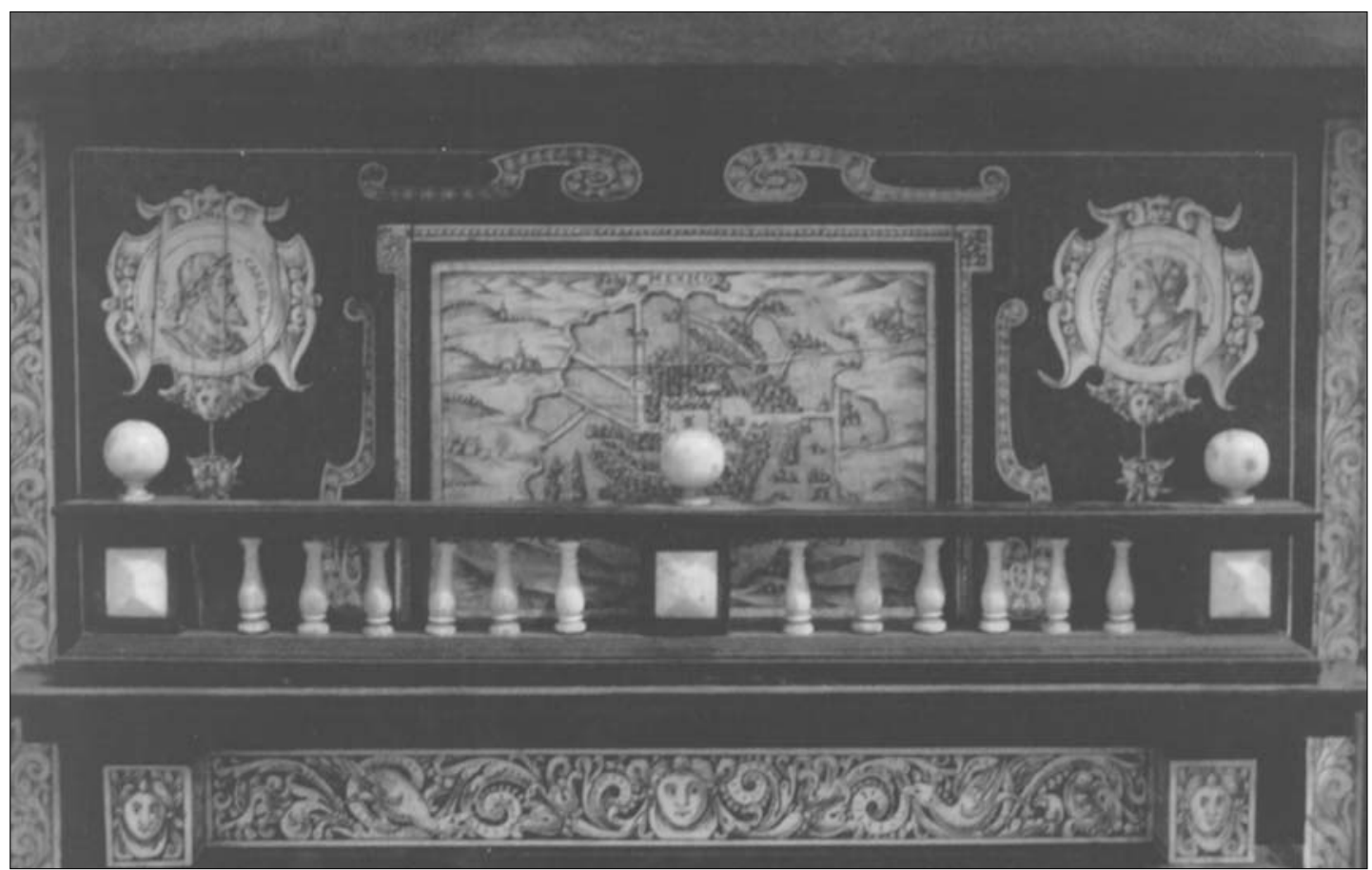

Figura 3. Vista de la ciudad de Méjico entre las efigies de Carlos Ve Isabel de Portugal. Detalle del cuerpo central.

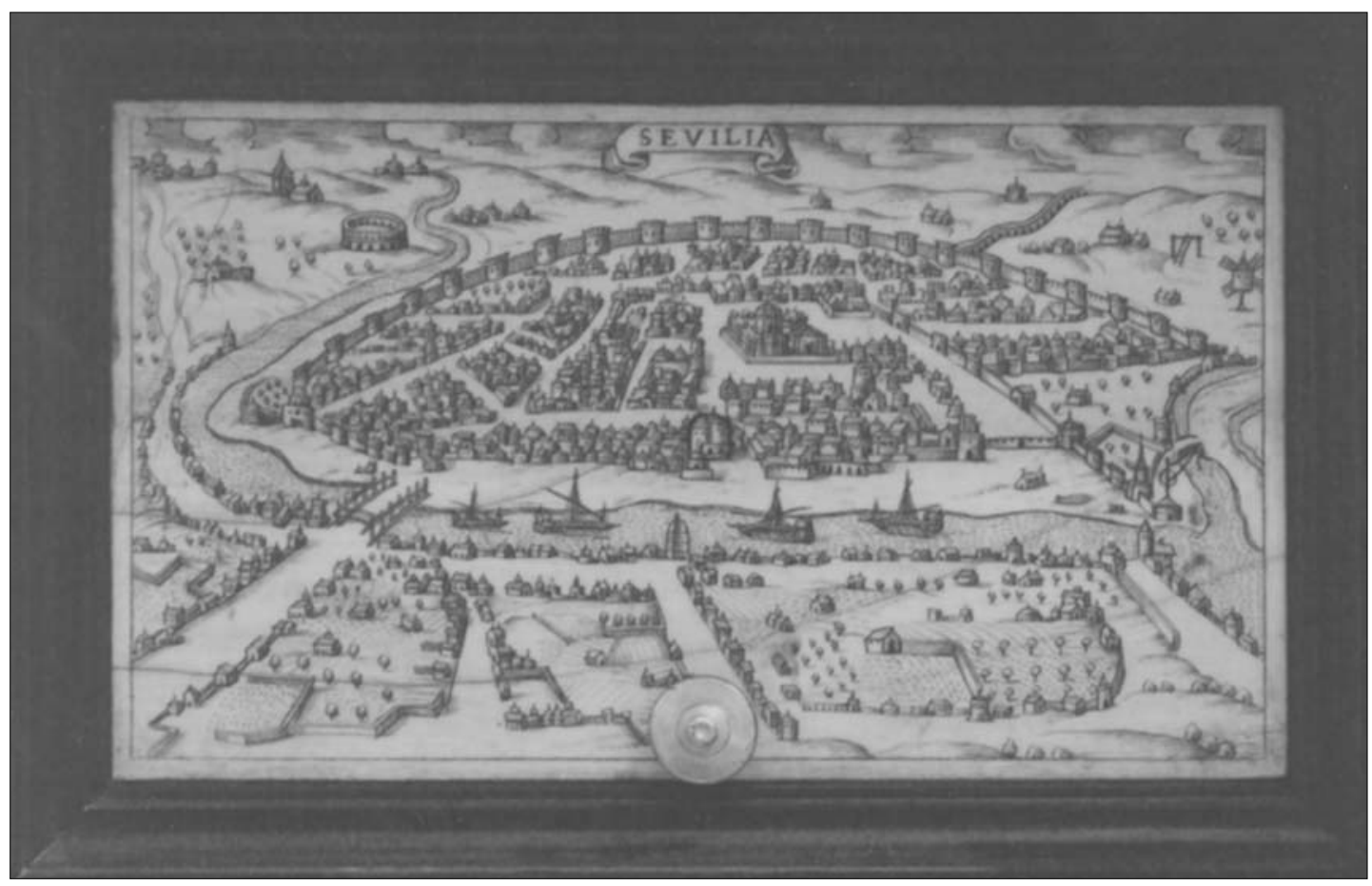

Figura 4. Vista de Sevilla. Detalle de una de las gavetas.

AEA, LXXIX, 316, OCTUBRE-DICIEMBRE, 403-425, 2006, ISSN: 0004-0428 
minghi se utilizaron con fines decorativos 12 . Podemos recordar aquí que uno de los llamados cosmógrafos del Rey, fue precisamente Antonio Spano, el grabador en marfil citado más arriba en relación con otro escritorio. Si en el de 1611 son las efigies de los Reyes Católicos las que los flanquean el plano de Madrid en el cajón central, aquí son el emperador y su esposa los que acogen la vista de Méjico (fig. 3). Llama la atención en todas ellas sobre todo en las tomadas del volumen primero de Hogenberg, gran parte de las construcciones se repiten casi iguales, mostrando interés por las murallas y las tierras de labor al exterior de las ciudades. Si exceptuamos a París el resto de las ciudades representadas, sí parecen aquí tener un cierto sentido si no simbólico,

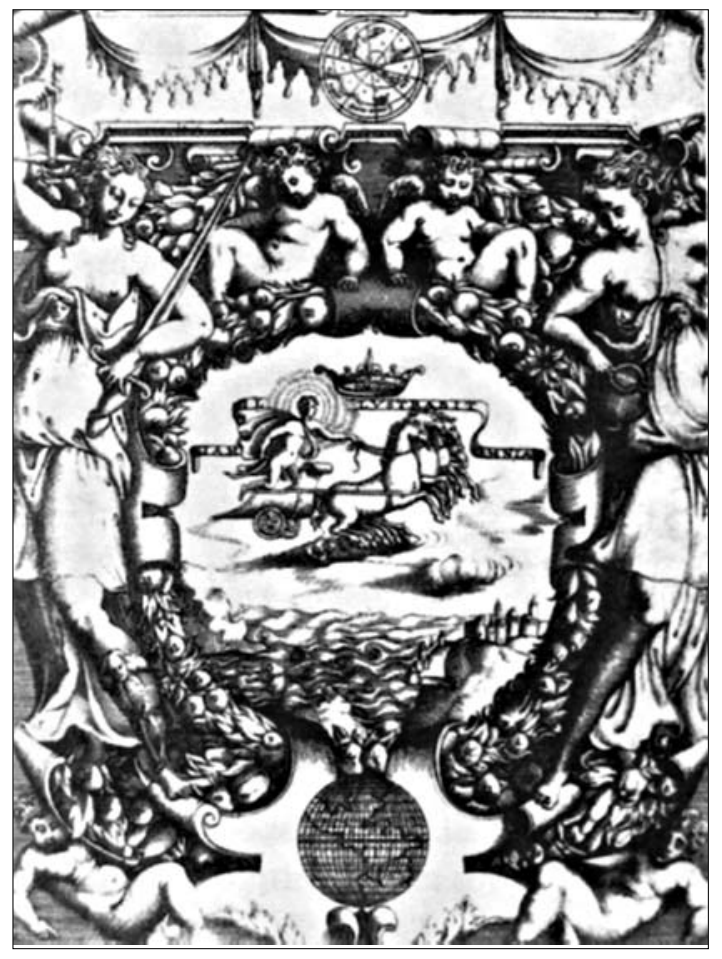

Figura 6. J.Ruscelli. Divisa de Felipe II ed.1583. Copyrightœæ@Patrimonio Nacional.

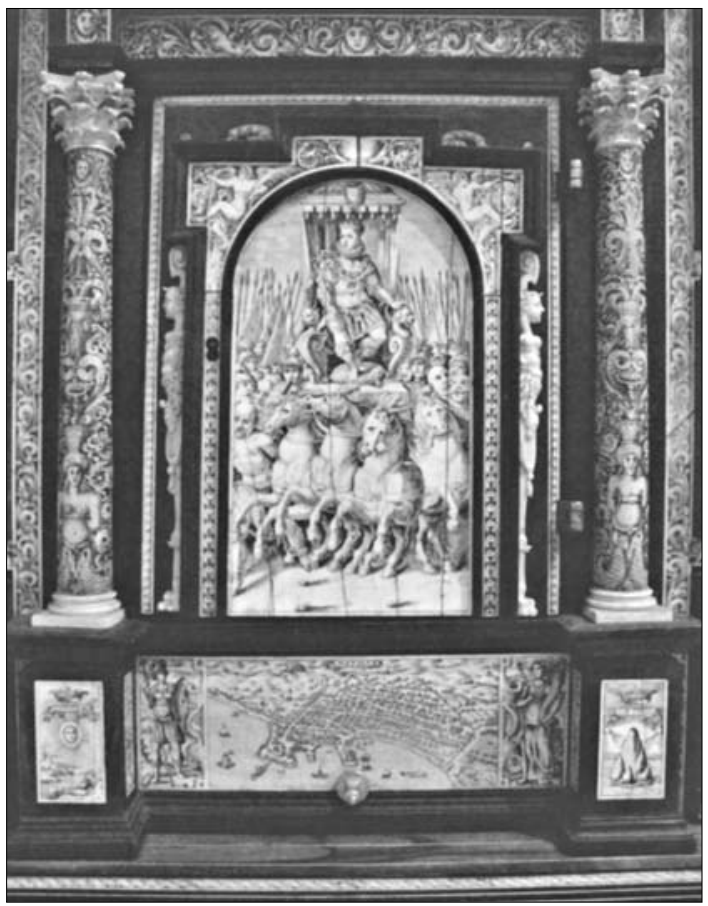

Figura 5. Representación de Felipe III. Detalle de la portada central.

si, al menos, de estrecha relación con el poder virreinal y con el control mediterráneo de ciudades como baluartes occidentales contra los turcos 13 .

La escena central en la que aparece en posición frontal un príncipe en un carro tirado por cuatro caballos blancos, imagen sin duda de Felipe III (fig. 5), se puede entender completándola con las placas situadas sobre los pedestales de las columnas. De un modo caleidoscópico, fragmentándola en cinco placas, se reproduce la divisa de Felipe II popularizada por Ruscelli en Delle Imprese illustri de 1560 (fig. 6), posiblemente tomada a su vez de la medalla realizada por Jacopo da Trezo en 1555 para conmemorar la boda de Felipe II con María Tudor, motivo bastante común en la medallística clásica. Aquí resulta interesante el

13 Da Seta, Cesare, La ciudad europea del siglo de Oro. Orígenes, desarrollo y crisis de la civilización urbana. Ed esp. Istmo 2002. pp. 10. 
desdoblamiento de la imagen de la medalla transformado el carro de Apolo en el trono de Felipe III y ampliando y simplificando el paisaje bajo el sol bajo la divisa IAM ILLVSTRABIT OMNIA. Ruscelli explica que "Il Re autor di questa impresa, aspirando all'altezza dell'animo suo \& alla perfettion della vera gloria...", cristianiza el sentido político de la empresa aludiendo al salmo XXXIII del profeta David ... "Accedite ad eum et illuminamini et facies vestra non confundetur". El sol pasa de ser imagen del príncipe que con la luz de la virtud ha de destruir las tinieblas del vicio, a ser imagen de Dios al servicio del cual Felipe II, con la claridad y esplendor de la Fe lucha contra la herejía ${ }^{14}$. Del mismo modo la utilizó Francesco Terzio en la Imagines gentis Austriacae en 1569 en el luneto de la imagen aparece el carro solar y la figura del rey acompañada de Hercules con la Hydra y Hercules y $\mathrm{Caco}^{15}$. Al ser incluida en el repertorio de Ruscelli, la divisa IAM ILLVSTRABIT OMNIA se convirtió en el lema más representativo del monarca junto al NEC SPE NEC METU que había utilizado en su primer viaje a Flandes. Lo que en Ruscelli es el carro solar bajo la corona aquí se reduce al rostro amable del Sol y las movidas aguas con Jerusalén a la derecha, aparecen aquí como un caudaloso y tranquilo río (fig. 7). Las dos figuras alegóricas situadas a los lados del emblema ruscelliano se separan aquí flanqueando la vista de la ciudad de Nápoles. Una imagen intermedia entre ambas la encontramos al interior de la puerta central del escritorio del mismo tipo, hoy en el Museo Poldi Pezzoli de Milán, idéntica al cuerpo central de la empresa con el carro solar tirado por los caballos ${ }^{16}$, trasladados en nuestro mueble a la portada central representando a Felipe III como "rey solar", que podría tener relación con el emblema que con el mismo lema y Apolo enarbolando una antorcha en un carro tirado por cuatro caballos y un sol al fondo, utilizó Gómez de la Reguera en 1678 en sus Empresas de los Reyes de Castilla ${ }^{17}$.

La segunda empresa que aparece en el mueble bajo el pedestal derecho con el mote $P R O$ BANTVR FORTES IMPETU (fig. 8), asimismo bajo la corona, con los vientos soplando con fuerza contra la roca inamovible que emerge de un tranquilo mar ${ }^{18}$, se encuentra tambien en Ruscelli, aunque con otro lema Semper idem perteneciendo al conde Escipion Porcellaga (fig. 10) ${ }^{19}$. Este tipo de empresa suele presentarse con una nave en un mar agitado por los vientos, así el emblema XLIII de Guillaume de la Perrière "siempre debe estar preparada la nave del estado para superar cualquier adversidad" 20 y así lo recoge Solórzano, para quien estos dos vientos son dos príncipes que con sus enfrentamientos turban las aguas del mar y representa a

14 Checa Cremades, F. Felipe II mecenas de las Artes. Madrid 1992 cap. III. p. 195.

15 Scheicher, E. "Die Imaginis gentis aiustriacae des Francesco Terzio" JKHSW. 79, 1983. 43 y ss. nº 37 ilust. 67.

16 Inventario no 731.a, en Balboni Brizza, Stipi e cassoni nel Museo Poldi Pezzoli. Milano. 1995. Catálogo no 8. Depositados en el museo desde 1981 y recogidos por A.Zanni en la Guía de 1988. En él la placa con el mapa del reino de Nápoles, ha sido trasladada al plano superior, presentando muchos aditamentos decimonónicos. Este mueble figuró en la exposición La civiltá del Seicento a Napoli en 1984, recogido en el catálogo pp 367-8 con el n ${ }^{\circ} 586$ y por González Palacios en Bolaffi Arte, 1975. En ambos se recoge que el primer documento conocido fue su aparición en la Exposizione Nazionale di Belle Artid: Torino 1880, como propiedad del conde Bertone.

17 Un estudio completo de la empresa de Ruscelli se encuentra en Victor Mínguez Los Reyes solares: iconografía astral de la monarquía hispánica. Castelló de la Plana. Universitat Jaume I. 2001.89-98, recogiendo todas las interpretaciones anteriores.

${ }^{18}$ La referencia a los vientos mediante niños soplando es común en el siglo XVI. Guy de Tervarent Attributs et symboles dans l'art profane. p. 358.

19 Ruscelli ed 1583 fol 490, siguiendo los versos de Ariosto "Inmóvil di vera FEDE scoglio / che d'ogni intorno il vento e'l mar percole percota...en las cosas honorables y virtuosas que pertenecen a un verdadero caballero y a un verdadero señor, no se hará violencia alguna...que pueda moverlo de la firmeza y disposición de animo que por sangre, familia, amigos y principalmente por su valor particular ...no hay duda que no podran faltar los contrarios que, por emulación, envidia o maldad, traten de derribarla

${ }^{20}$ Henkel-Scöne, Emblemata. Handbuch zur Sinnbildkunst des XVI und XVII Jahrhunderts Stuttgart 1967 no 1.461. 


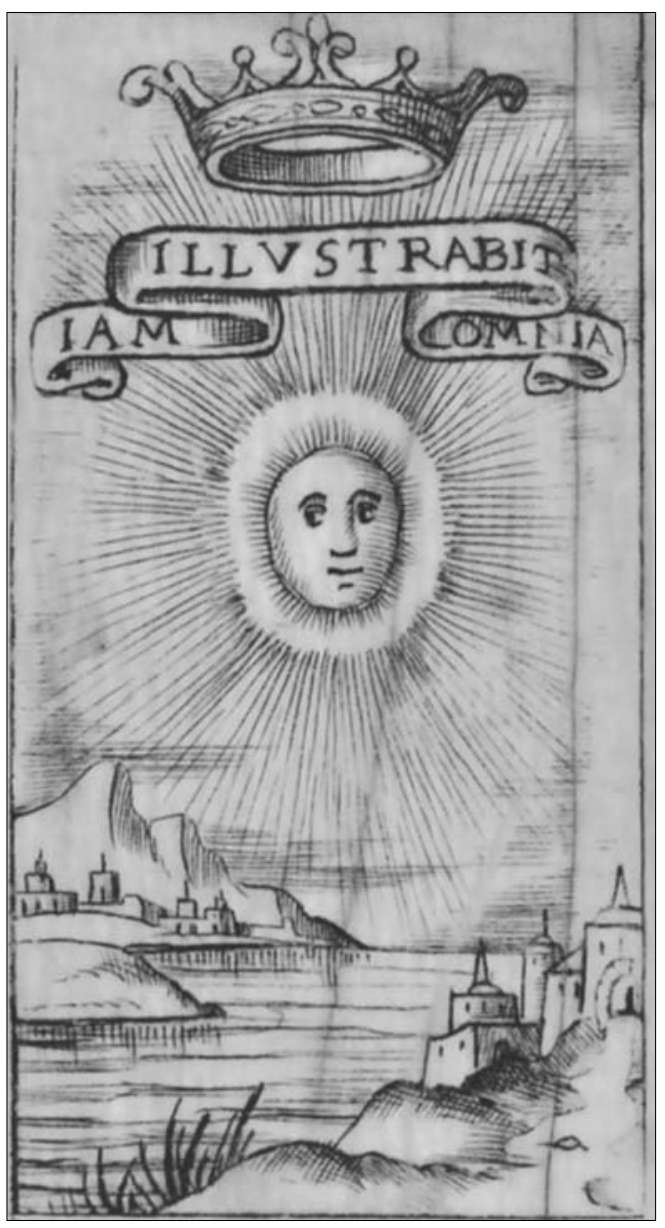

Figura 7. Empresa IAM ILLVSTRABIT OMNIA.

Detalle del pedestal izquierdo de la portada.

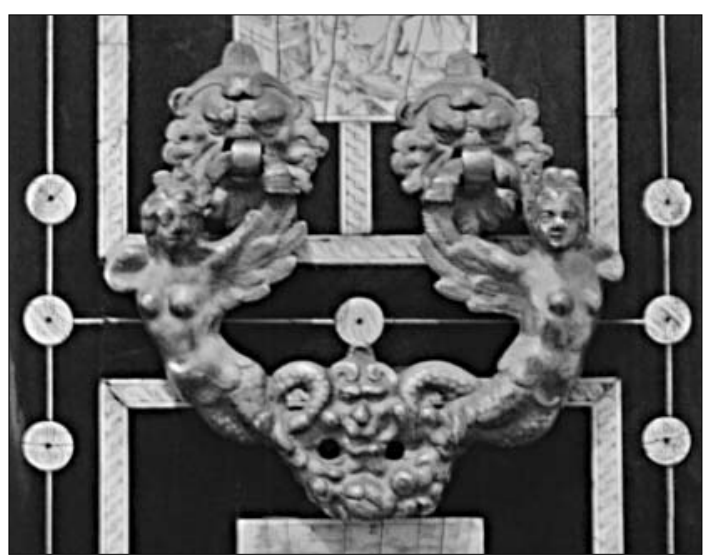

Figura 9. Asa de bronce. Lateral del mueble.

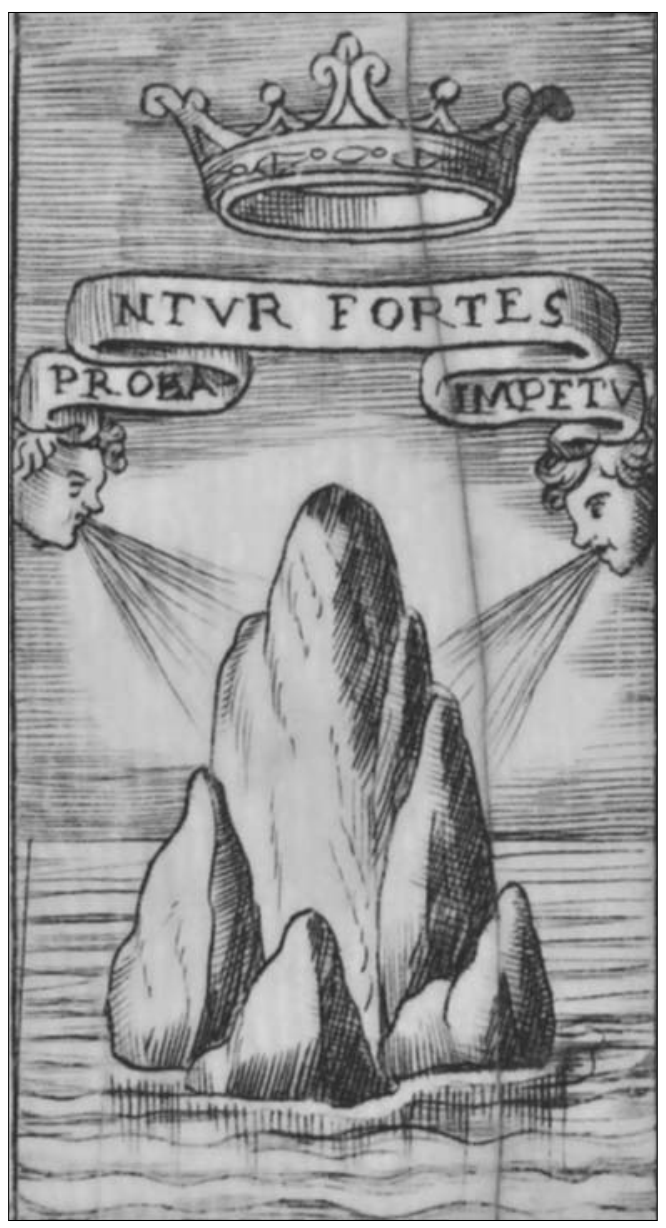

Figura 8. Empresa PROBANTVR FORTES IMPETV. Detalle del pedestal derecho de la portada.

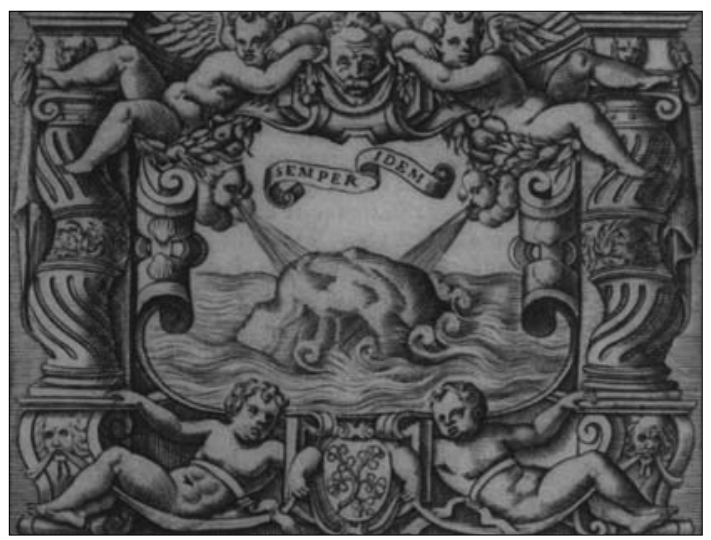

Figura 10. J. Ruscelli. Empresa del Conde E. Porcellaga Copyrightå@Patrimonio Nacional. 
la nave del estado zarandeada por ellos" imagen de los príncipes que enfrentándose son causa de desdichas y calamidades para su pueblo21.

Nuestra primera inclinación fue atribuir las empresas al posible destinatario del mueble, posiblemente don Juan Alfonso Pimentel VIII conde y V duque de Benavente, virrey de Nápoles entre 1603 y 1610 cuyo interés por las artes y al mismo tiempo por la emblemática ${ }^{22}$ apuntaban en esa dirección incluso en la tasación de sus bienes en Valladolid, figuran "un escritorio grande de marfil y ébano con clavazón dorada y otro igual con unas figuras, vasas y capitales de relieve de marfil..., tasado en seis mil reales" 23 . Las dos empresas parecen pertenecer a una persona real al estar coronadas $^{24}$ y al corresponder la primera al rey Felipe II, la segunda, tan similar de concepto, si no fue inventada, tuvo que pertenecer al mismo rey, o bien, con un origen desconocido por el momento, al monarca reinante en el momento, Felipe III. Incluso podría ser que esta fuese utilizada en una, hasta ahora desconocida, empresa de don Juan Alfonso Pimentel, VIII conde-duque de Benavente.

El mueble, pues, corresponde realmente a las fechas de estancia napolitana de este virrey, y es sin duda producto de un segundo taller que se especializó en este tipo, con evidente relación con el de los renombrados artistas flamencos e italianos conjuntamente, citados más arriba, que realizaron los ejemplares del primer grupo siendo asimismo el único conocido que conserva los herrajes de bronce, por lo que podría darse como válida su pertenencia en origen al conde de Benavente, bien por compra o regalo durante su estancia en Nápoles.

María PaZ Aguiló INSTITUTO DE HisTORIA. CSIC

\footnotetext{
${ }^{21}$ Emblema XC -Regum bella populos quassant, quien utiliza al viento Noto (Ilíada como viento del sur) con un claro sentido destructor, mientras que Boreas esta relacionado con las tormentas marinas, véase Perez de Moya Philosophia secreta lib. II cap. XXXV.

22 Como se indica en el artículo de Mercedes Simal López "Don Juan Alfonso Pimentel, VIII Conde Duque de Benavente y el coleccionismo de antigüedades: inquietudes de un virrey de Nápoles" Reales Sitios n 164, 2005.

23 García Chico, E. Documentos para el estudio del arte en Castilla, tomo III, 1946, p. 394. Ni en el inventario de Madrid de 1622, ni en el de 1666 en Benaventer ni en el de 1701 de Madrid vuelve a aparecer, aunque en este sí figuran varios escritorios de ébano. M. Simal Los condes-duques de Benavente en el siglo XVII. Patronos y coleccionistas en su villa solariega. Centro de Estudios Benaventanos, Benavente 2002, documentos 16, 22 y 28.

${ }^{24} \mathrm{Si}$ bien la corona parecía no pertenecer a un rey de la casa de Austria, el que aparezca exactamente igual en la empresa de Catalina de Medicis, reina de Francia (Ruscelli, Imprese fol 117) y en otras de reyes, permite suponer que se ha utilizado de modo genérico.
} 